\title{
FEASIBILITY STUDY TO UPDATE ANNUALIZED COST OF LEAVING (ACOL) PROCEDURES AT THE NAVY PERSONNEL RESEARCH AND DEVELOPMENT CENTER (NPRDC)
}

\author{
David Trumble \\ Deborah M. Flanagan \\ Energy Division \\ Oak Ridge National Laboratory \\ DATE PUBLISHED: DECEMBER 1990
}

Research sponsored by the

Navy Personnel Research and Development Center

\author{
Operated by \\ OAK RIDGE NATIONAL LABORATORY \\ Oak Ridge, Tennessee 37831-6205 \\ managed by \\ MARTIN MARIETTA ENERGY SYSTEMS, INC. \\ for the \\ U. S. DEPARTMENT OF ENERGY \\ Under Contract No. DE-ACO5-840R21400
}




\section{TABLE OF CONTENTS}

ABSTRACT $\ldots \ldots \ldots \ldots \ldots \ldots \ldots \ldots \ldots \ldots \ldots \ldots \ldots \ldots \ldots \ldots \ldots \ldots$

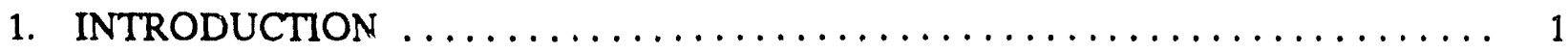

2. BACKGROUND $\ldots \ldots \ldots \ldots \ldots \ldots \ldots \ldots \ldots \ldots \ldots \ldots \ldots \ldots \ldots \ldots \ldots$

2.1 HISTORY OF PERSONNEL RETENTION MODELS $\ldots \ldots \ldots \ldots \ldots \ldots \ldots \ldots, 3$

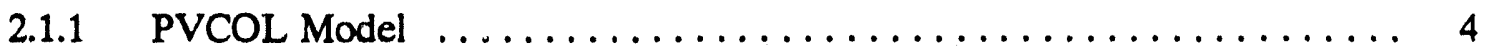

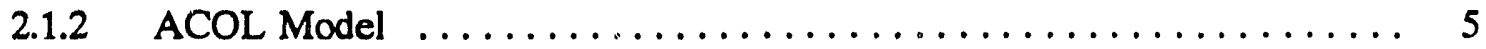

2.1.2.1 ACOL as an extension of PVCOL ............... 5

2.1.2.2 Estimated ACOL Models ................... 6

2.1.2.3 Career Models ........................ 6

2.1.2.4 Summary ......................... 8

2.1.3 Single Decision Models $\ldots \ldots \ldots \ldots \ldots \ldots \ldots \ldots \ldots \ldots \ldots \ldots \ldots$

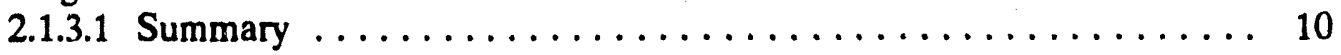

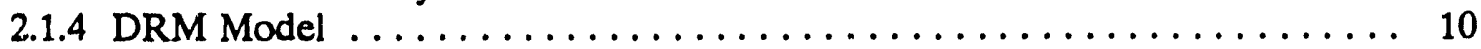

2.2 SCOPE OF OFFICER MANPOWER ANALYSIS $\ldots \ldots \ldots \ldots \ldots \ldots \ldots \ldots \ldots$

2.3 HISTORY OF NPRDC OFFICER LOSS RATE FORECASTING $\ldots \ldots \ldots \ldots 12$

3. APPROACH TO MODEL SELECTION $\ldots \ldots \ldots \ldots \ldots \ldots \ldots \ldots \ldots \ldots \ldots$

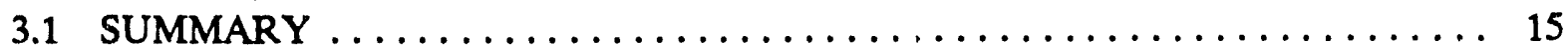

3.2 MODELING OBJECTIVE: FORECASTING VS SIMULATION $\ldots \ldots \ldots \ldots \ldots 15$

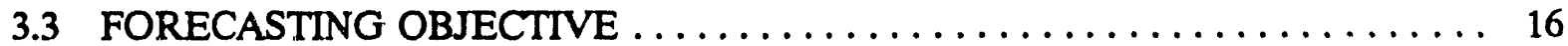

3.4 SIMULATION OBJECTIVE: THEORETICAL VS EMPIRICAL $\ldots \ldots \ldots \ldots \ldots 17$

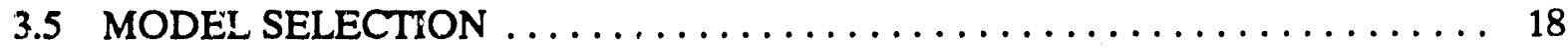

4. ALTERNATTVE MODELING DIRECTIONS: FOR RETIREMENT $\ldots \ldots \ldots \ldots .21$

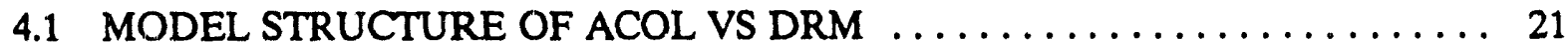

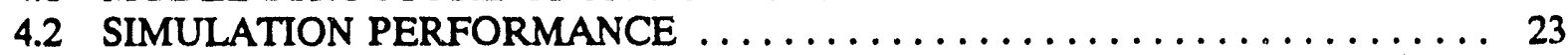

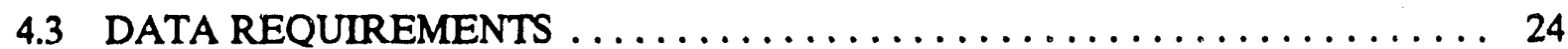

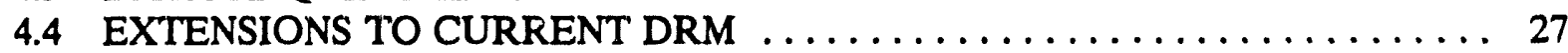

4.5 COMPUTATIONAL ISSUES WTTH CURRENT DRM IMPLEMENTATION . . 28

4.6 ADDITIONAL INFORMATION OF INTEREST $\ldots \ldots \ldots \ldots \ldots \ldots \ldots \ldots .28$

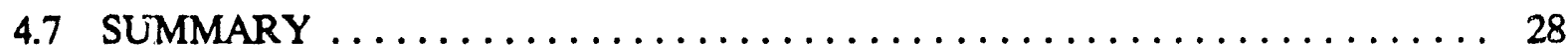

5. ALTERNATIVE MODELING DIRECTIONS: FORECASTING FOR

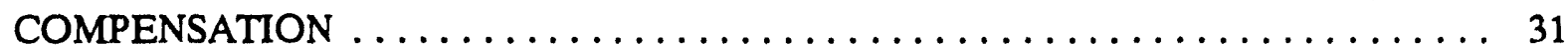

5.1 SIMULATING CHANGES IN CURRENT COMPENSATION $\ldots \ldots \ldots \ldots \ldots \ldots 31$

5.1.1 Regular Military Compensation, $\mathrm{RMC} \ldots \ldots \ldots \ldots \ldots \ldots \ldots \ldots \ldots \ldots \ldots \ldots$

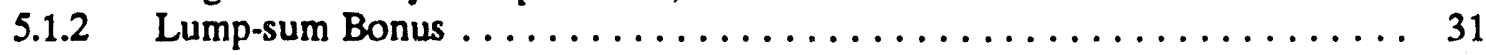

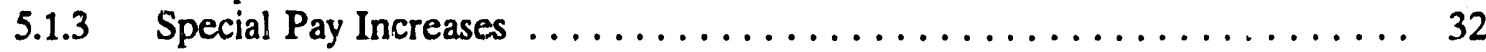

5.2 ALTERNATIVE MODEL FEATURES $\ldots \ldots \ldots \ldots \ldots \ldots \ldots \ldots \ldots \ldots$ 
5.3 FORECASTING ISSUES: SHORT-TERM AND MIDTERM MANPOWER AVAILABILITY $\ldots \ldots \ldots \ldots \ldots \ldots \ldots \ldots \ldots \ldots \ldots \ldots \ldots \ldots, 33$

5.4 UNIVARIATE MODELS $\ldots \ldots \ldots \ldots \ldots \ldots \ldots \ldots \ldots \ldots \ldots, \ldots \ldots \ldots$

5.5 MULTTVARIATE MODELS $\ldots \ldots \ldots \ldots \ldots \ldots \ldots \ldots \ldots \ldots \ldots \ldots \ldots, 35$

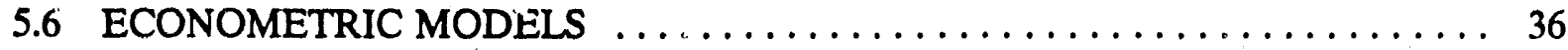

5.7 COMBINING FORECASTS FOR A GIVEN LENGTH FORECAST HORIZON 36

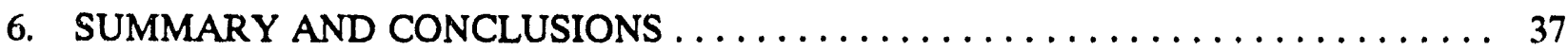

6.1 CONCLUSIONS RELATIVE TO THE NPRDC ENVIRONMENT $\ldots \ldots \ldots \ldots, 37$

6.2 CONCLUSIONS FOR MODEL SELECTION APPROACHES ............ 41

6.3 CONCLUSIONS FOR ALTERNATIVE MODELING DIRECTIONS: THE ACOL MODEL VS DRM ............................. 43

6.4 CONCLUSIONS FOR FORECASTING ALTERNATTVES TO THE DRM OR ACOL MODEL ............................... 44

6.5 CONCLUSIONS FOR VARIABLES TO CONSIDER FOR THE UPDATED MODEL ................................... 45

6.6 CONCLUSIONS FOR ALTERNATE CIVILIAN DATA CONSIDERATIONS .. 45

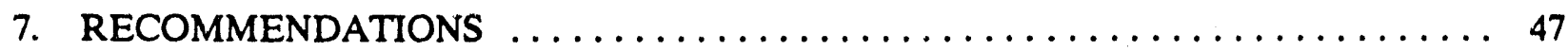

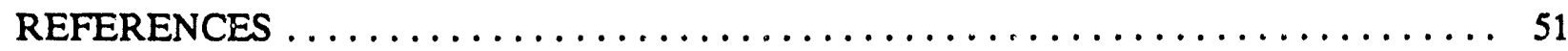




\section{ABSTRACT}

Accurate forecasts of officer retention rates are required in order to shape correctly the size and internal structure of the Navy manpower force through accession, promotion, and related policies. This study, conducted in 1987 for the Navy Personnel Research and Development Center (NPRDC), reviews existing forecasting and simulation methodologies and suggests new methods to implement in the future in order to improve forecasts of naval officer retention rates. The study also considers alternative sources of data to capture civilian earnings opportunities in the models. Two major types of models - Annualized Cost of Leaving (ACOL) and Dynamic Retention (DR) - are discussed in detail with respect to the ability to model and evaluate manpower policies of interest to NPRDC

staff. A variety of other techniques which should be considered during the estimation stage are also discussed. 


\section{INTRODUCTION}

The annualized cost of leaving (ACOL) model is the official forecasting model used by the Office of the Assistant Secretary of Defense, the Navy, and the Air Force to provide personnel lossrate forecasts at various levels of disaggregation. The model is used to evaluate alternative compensation proposals by providing loss-rate forecasts to another model, the Structured Accession Planning Model for Officers (STRAP-O). In 1987, the data, variables, and estimation techniques of the ACOL model within STRAP-O needed to be updated and revised. The Navy Personnel Research and Development Center (NPRDC), which is responsible for the ACOL forecasts, requested that Oak Ridge National Laboratory propose (a) aliernative data sources and techniques to estimate civilian earnings opportunities, (b) alternative econometric techniques to estimate the ACOL parameters, and (c) additional variables for inclusion in the forecast equations. This report documents that study.

The general study approach involved researching the subject area, the current data, the current models, and current estimation procedures. Available data and methodologies were then compared with the NPRDC problem in order to recommend potential solutions. This study did not include data collection or data analysis. Actual estimation of equations using various methodologies also was not a part of the project. This study, without data analysis, servis as a preliminary review and consideration, that is, a feasibility study, of methods and data to be tested at some future time.

This report is organized in eight sections. The Background Section discusses the history of officer retention models, the scope of officer manpower analysis at NPRDC, and NPRDC's history of officer loss-rate forecasting. Section 3 discusses the approach to model selection, which includes discussions on modeling requirements for simulation versus forecasting objectives and other model selection issues. Alternative modeling directions for simulation studies are included in Section 4 in 
addition to a thorough discussion of the Dynamic Retention Model (DRM) and a comparison of the DRM and ACOL model. Section 5 presents alternative modeling directions for forecasting and a summary of compensation policy issues. The summary and conclusions appear in Section 6, and recommendations are in Section 7. References are in Section 8. 


\section{BACKGROUND}

\section{HISTORY OF PERSONNEL RETENTION MODELS}

This section describes the most commonly used behavioral retention models. The two related models, the present value of cost of leaving (PVCOL) model and the annualized cost of leaving (ACOL) model, are discussed first. Next the various empirical implementations of the ACOL model are discussed. We then address the Dynamic Retention model (DRM), which probably rupresents the state of the art in modelling officer retention.

To expedite the following presentation we attempt to use a common set of notation. Because of the DRM formulation we denote feasible grade/length of service (LOS) combinations as states, $s=1, \ldots, N$. The notation is as follows:

\begin{tabular}{|c|c|c|}
\hline B & $=$ & discount factor, \\
\hline cpay $_{\$, j}$ & $=$ & $\begin{array}{l}\text { expected civilian pay for an officer who left the service in state s with } \\
\text { i total years of experience (LOS plus post service years) since } \\
\text { entering the service, }\end{array}$ \\
\hline mpay. & $=$ & expected active duty military pay in state $s$, \\
\hline rpay, & $=$ & expected military retirement pay for an officer in state s, \\
\hline spay, & $=$ & $\begin{array}{l}\text { expected scverance pay associated with involuntary separation for an } \\
\text { officer leaving in state } s \text {, }\end{array}$ \\
\hline $\operatorname{los}(\mathbf{s})$ & $=$ & the LOS associated with state s, \\
\hline Sur $_{\mathbf{i j} \mathbf{j}}$ & $=$ & probability in state $\mathrm{i}$ of surviving $(\mathrm{i}-\operatorname{los}(\mathrm{i}))$ additional years, \\
\hline $\mathbf{s s}(\mathrm{h})$ & $=$ & $\begin{array}{l}\text { the most likely state for an office, with } \operatorname{LOS}=h, h=1, \ldots, 32 \text { years of } \\
\text { service. }\end{array}$ \\
\hline
\end{tabular}




\subsection{PVCOL Model}

The model assumes officers elect either to stay or leave each period depending on which action yields the highest present discounted value. It is also assumed that there is no uncertainty about the future. The optimal length of service for each officer can, therefore, be determined and used in alculating the value of staying in the service. This value is then compared to the value of leaving, assuming civilian employment.

The return from leaving for an officer in state $s$ is

$$
L_{s}=\sum_{j=l o s(s)+1}^{\infty}\left(\text { cpay }_{s, j}+r p a y_{s}\right) \beta^{j} \cdot \operatorname{Sur}_{s j} .
$$

We note that both cpay $_{a, j}$ and Sur ${ }_{a, j}$ go to zero as j gets large, reflecting the retirement and death of the civilian worker.

The return from staying is

$$
S_{s, h}=\sum_{n=l o s(s)+1}^{h} \beta^{n} \cdot \operatorname{Sur}_{s, n} \cdot \text { mpay }_{\text {so(n) }}+L_{s(h)} \cdot \beta^{h} \cdot \operatorname{sur}_{s, j},
$$

for a career of $h$ years in the service, where $s s(h)$ is defined as the mostly likely state for LOS at $h$ years. The present value cost of leaving in state s can then be expressed as

$$
\text { PVCOL, }=\max \left(\underset{h}{\left(S_{s}, h\right)}-L_{s}\right.
$$

where the maximization with respect to h determines the officer's optimal career length.

In implementing this model it is assumed that for each period a random shock, $e$, occurs which is identically, independently, logistically distributed with mean $\mu$ and standard deviation 1.8137o. An officer's decision to stay therefore requires that

$$
\mathrm{PVCOL}_{3}+\mathrm{e}>0
$$


The retention probability, $r_{s}$, can then be written as

$$
r_{s}=\int_{0}^{\infty} f(\varepsilon \mid \mu, \sigma) d \epsilon=1+\exp \left[\left(P C O L_{s}-\mu\right) / \sigma\right]^{-1}-P V C O L_{i},
$$

where $f($.$) is the logistic distribution.$

\subsection{ACOL Model}

\subsubsection{ACOL as an extension of PVCOL}

The ACOL model is an extension of the PVCOL model which incorporates a taste for the service, denoted $\phi_{\mathbf{k}}$. This parameter reflects the annual nonpecuniary return associated with military life. The returns from staying in state $s$ for officer $k$ for a total of $h$ years is then

$$
s_{k, s h}=\sum_{n=l o s(s)+1}^{h} \beta^{n} \cdot \operatorname{sur}_{s, n} \cdot\left(\operatorname{mpay}_{s v(n)}+\phi_{k}\right)+L_{s s(h)} \cdot \beta^{h} \cdot S u r_{s, h},
$$

where $\mathrm{L}_{\mathrm{h}}$ is described by (2.1) above. The annualized cost of leaving, denoted $\mathrm{ACOL}_{\mathrm{a}}$ for state $s$ and career length $h$, is determinard as the $\phi$ value which equates the returns from staying and leaving. Solving

$$
S_{k s, h}-L_{s}=0
$$

for $\phi$ yields

$$
A C O L_{s, h}=\frac{\sum_{n=i+1}^{h}\left(\operatorname{mpay}_{s o(n)} \cdot \beta^{n} \cdot \operatorname{Sur}_{s, h}\right)+L_{h} \cdot \beta^{h} S u r_{s, h}-L_{s}}{\sum_{n=i+1}^{h} \beta^{n} \cdot \operatorname{Sur}_{s, n}} .
$$

We note that the numerator of this expression is the simple $\mathrm{PVCOL}_{a, b}$. The optimal length career is then chosen to maximize $\mathrm{ACOL}_{\mathbf{a h}}$

$$
A C O L_{s}=\max _{h}\left(A C O L_{s h}\right)
$$


The model is implemented for empirical use by assuming that tastes are logistically distributed [denoted here by $g(\phi)$ ]:

$$
r=\int_{-A C O L_{s}}^{\infty} g(\phi \mid \mu, \sigma) d \phi=1+\exp \left[\left(A C O L_{s}-\mu\right) / \sigma\right]^{-1}
$$

\subsection{Estimated ACOL Models}

The various empirical implementations of the ACOL model are briefly reviewed in this subsection. Univrtunately, the majority of these studies are concerned with enlisted personnel. The studies are, therefore, divided into two groups to focus on those most likely to be useful in modelling officer retention. The first group contains career models in that retention rates over a range of LOS are modelled. The second group is devoted to models of retention rates at a particular LOS. This second group contains single decision models which usually model either the first or second term reenlistment decision when focusing on the effect of bonus payments.

\subsection{Career Models}

Warner (1979) estimated an ACOL type model for enlisted personnel in all four branches of the services with $\mathrm{LOS}=4, \ldots, 16$ using fiscal year (FY) 1977 data. Warner states that observations with LOS $=17, \ldots, 19$ were not used because geometric grc wtis in the ACOL variable would yield biased estimates of the ACOL coefficient. Warner notes that the constant term is not the same for each grade/LOS combination. Therefore, additional terms such as LOS and $\ln ($ LOS) are included. Using grouped data, a logit regression model of the form

$$
\log \frac{r_{i t}}{1-r_{i t}}=\alpha_{0}+\alpha_{1} A C O L_{i t}+\alpha_{2} \ln (\operatorname{LOS}(i))+\alpha \text { ServiceDummies, }
$$

which was estimated by Orrinary Least Squares (OLS). Warner states that the weighted OLS method to adjust for different cell population sizes was not employed because the cell sizes were large 
(greater than a thousand). Estimates of the model for $\operatorname{LOS}=4, \ldots, 16$ are reported in addition to estimates over the two separate LOS ranges, $4, \ldots, 9$ and $10, \ldots, 16$. The model parameters do not appear stable, although no test statistics are presented. The same estimates are presented in Warner (1984). Warner suggests including a lagged sCOL term in the above specification. The estimated model did not include such a term because of the cross-sectional sample used. Warner and Simon (1979), as discussed below, do estimate a lagged ACOL coefficient. The ACOL variable in Warner's studies is computed with a ten percent discount rate. Civilian earnings are approximated by average civilian earnings of male high school graduates by age usirig the Current Population Survey.

Smoker (1984) estimated ACOL type models for both officers and enlisted personnel in all branches of the service. Grouped data were used to produce logit regression models of the form

$$
\log \frac{r_{i j}}{1-r_{i j}}=\alpha_{0}+\alpha_{1} A C O L_{i t}+\alpha_{2} D(\operatorname{LOS} \leq 5)
$$

which includes a dummy variable set equal to one when LOS is less than or equal to five, and set equal to zero otherwise. The model was estimated for several alternative assumptions about the structure of discount rates. The results indicate that the estimated ACOL coefficient is particularly sensitive to the assumed discount rate structure.

Estimates of occupation-specific civilian earnings were used in the calculation of ACOL. Civilian earnings were projected using a wage equation estimated by occupation with 1980 census data. The log of wage earnings by age group is specified as linear function of age, age squared, education dummies, and the percent black.

Kostiuk (1985) estimated an ACOL type model for Marine aviators, pooling both captains with $\operatorname{LOS}=6, \ldots, 10$ and majors with $\operatorname{LOS}=11, \ldots, 14$. These $\operatorname{LOS}$ groups were selected because they are considered the critical years for retaining officers and filling operational flying requirements. Also 
Kostiuk notes that officers with LOS $\geq 14$ years are mostly concerned with retirement and not marginal pay changes. The ACOL model is estimated by OLS as

$$
\log \frac{r_{i t}}{1-r_{i t}}=\alpha_{0}+\alpha_{1} A C O L_{i t}+\alpha_{2} \text { Pilots }_{t}+\alpha D(L O S-7)+\ldots+\alpha D(L O S-14)
$$

where the variable Pilots is the change in the number of pilots employed by civilian airlines. An alternative specification which uses the civilian unemployment rate instead of Pilots is also reported. The pilots specification yields a slight improveme it in fitting the data.

Kostiuk also calculated ACOL with a ten percent discount rate. Estimates of civilian earnings were based on data by the Airline Pilots Association. The log of wages is estimated each year by OLS as a third order polynomial function of flying experience. The estimated equation was then used to predict the expected lifetime earnings for those leaving the Marine Corps.

\subsection{Summary}

The theory of the ACOL model is not sufficient for empirical application. All three applications incorporate some function of LOS in the estimated specification. Warner's results suggest that the ACOL coefficient is not constant with respect to LOS. This important hypothesis is not tested in any of the reviewed studies. Also, Smoker's study indicates the sensitivity of the ACOL coefficient to aliernative discount rate assumptions. Both Warner and Kostiuk do not recommend applying the ACOL model over the range $\mathrm{LOS}=17, \ldots, 20$.

\subsubsection{Single Decision Models}

Warner and Simon (1979) model first and second term reenlistment decisions separately for Navy enlisted personnel with an ACOL type model. The data contain all individuals who made firstand second-term reenlistment decisions in the period FY 1974-1978. Extensions of luss than three years are not included. Warner reports that the inclusion variables, such as marital status, fiscal year dummies, education level, and race, do not in most cases change the ACOL coefficient. In modelling 
second-term enlistment they focus on the effects of first-term bonuses on: second-term reenlistment. To handle this effect the estimated ACOL model includes a lagged ACOL variable.

Using the same data set, Warner and Goldberg (1981) also develop and estimate a model of first-term reenlistment decisions. A major focus of the analysis is the effect of sea duty on retention. The authors note that there is little variation in the extent of sea duty within occupation. Consequently, the effect of sea duty can only estimated as a cross-sectional relationship and cannot be examined by time series analysis.

Warner and Goldberg (1982) model enlisted Navy extension as well as reenlistment rates for first-term and second-term decisions. Extension is defined as a commitment of three years or less as compared to a four- or six-year reenlistment commitment. The data used for estimation cover the period FY 1974-1980. The second-term specification includes the first-term bonus variable.

Hosek and Peterson (1985) also model both extension and reenlistment decision for first and serond term decisions separately. However, an ACOL approach was not used. Instead, a Military/Civilian wage index and bonus variables reflecting the amount and method of payment were constructed. The data consisted of grouped data for all enlisted military occupation over the period FY 1976-1981.

Carter (1985) models the conditional probability of a particular length commitment given reenlistment as a function of bonus payments, LOS, and demographic factors. The estimated model provides an indication of the effectiveness of bonus incentives given reenlistment. The effect of bonuses on the reenlistment decision is not addressed but will be incorporated in Rand's inventory projection model for the Air Force. Longitudinal data of enlisted airmen ove- the FY 1979 period were used. 


\subsubsection{Summary}

Warner shows that the ACOL model for enlisted personnel should include lagged bonus variables. The formulation of Hosek and Peterson using a military/civilian wage index provides a simplified alternative to ACOL.

\subsection{DRM Model}

The DRM takes the maximizing behavior paradigm much further in modeling the officer career decision process. Two types of nonpecuniary returns are explicitly modeled: $(1)$ tastes $\phi$, which are constant over time and whose value is known to the officers; and (2) random shocks $e$, which are identically, independently distributed over time, and officers know about the current value of the random shock and its probability distribution function. It is assumed that officers know promosion probabilities and pay schedules. Civilian earnings are also assumed known.

The expected discounted return from leaving is given by

$$
L_{s}=\sum_{j=\operatorname{los}(s)+1}^{\infty}\left(\text { cpay }_{s j}+\operatorname{ppay}_{s}\right) \operatorname{Sur}_{s j} \cdot \beta^{j} .
$$

Let $V\left(s, \phi_{k}, c_{h, k}\right)$ be the expected discounted return when the kth officer is in state $s$, has taste parameter $\phi_{\mathrm{k}}$, has just drawn random shock $e_{2, k}$ ar 1 follows an optimal retention policy. If the officer stays he collects $e_{1, k}$ and moves from state $s$ to $j$ according to the transition probability $P_{a, j}$. The officer receives either mpay $+\phi_{k}$ for staying in the service or spay, for involuntary separation or retirement. He then makes the stay/eave decision, again receiving the optimal return $V_{1+1}\left(s, \phi_{k}, e\right)$. The expected returns from staying are thus

$$
\begin{aligned}
S_{k s}= & e+M_{k, s}, \\
M_{k, s}= & \sum_{j=s}^{N-1} P_{s j}\left\{\text { mpay }_{j}+\phi_{k}\right\} \cdot \beta+E_{e}\left\{V\left(j, \phi_{k}, e\right)\right\} \\
& +P_{s, N}\left\{\text { spays }+L_{s}\right\},
\end{aligned}
$$


where $E_{e}$ denotes the expectation with respect to the random term 6.

The optimal stay/leave decision is then determined as

$$
V\left(s, \phi_{k}, e_{k s}\right) \text { is } \operatorname{Mar}\left\{S_{k, s}, L_{s}\right\}
$$

The model is implemented for empirical use by specifying the probability functions $F(e)$ and $\mathrm{g}\left(\phi_{\mathrm{k}}\right)$. It is assumed that $\mathrm{F}$ is a cumulative normal distribution with mean zero and standard deviation $\sigma_{e}$. The taste distribution is assumed to follow the extreme value distribution with scale parameter $\mu$ and location parameter $\Phi$. Gotz and McCall (1983) note that the Air Force observes performance and offers a regular commission to an officer if his perfonnance is sufficiently high. As a result, the underlying distribution of tastes among officers receiving regular commissions will be different from those officers failing to receive commissions. Gotz and McCall incorporate this observation into the model by developing a condition distribution of tastes given the officer's commission status. This distribution is specified as a function of the observed fraction of officers, $p$, who are granted regular commissions in a given year group and a selectivity parameter $\alpha$. An important property of this specification is that as $\alpha$ increases, the value of tastes decreases in the commissioning decision. In the limit as $\alpha$ goes to infinity, tastes do not matter, so that each officer has an equal chance of being given a regular commission.

The four parameters $\sigma_{e}, \mu, \Phi$, and $\alpha$ are estimated by maximum likelihood using longitudinal data. Gotz and McCall pool nine aeronautical commission groups assuming a common $\sigma_{e}$ value. For comparison purposes the basic two-parameter ACOL model was also estimated. Not surprisingly, the DRM model is found to fit the data better.

\subsection{SCOPE OF OFFICER MANPOWER ANALYSIS}

The Navy's officer manpower managers are faced with the task of equating the dynamic supply and demand of officers. Managers can directly shape the size and internal structure of the force through accession, promotion, and related policies. An important tool in accomplishing this task 
is the officer projection (OPRO) model. Successive projections of annual end strength by community, grade, and length of service (LOS) are generated by this model from a set of personnel flow inputs. The use of this model includes assessment of feasibility of manpower goals, construction of "zones of executability" (ZOEs), development of promotion plans, and the analysis of policy changes or special programs. ZOEs establish maximum and minimum achievable force sizes from a variety of policy scenarios reflecting Navy, DOD, and Congressional guidance.

The projections cover a total of thirty-two communities, nine grades and thirty-one years of service over a seven-year forecast horizon. Because many of the grade/LOS inventories are always zero, the total number of possible loss ،ates, $6417(=32 \times 31 \times 9)$, can be reduced to roughly 1,288 $(=32 \times 56)$.

The two basic inputs are promotion plans and predicted loss rates, with loss rates being the one major factor not directly controllable by the manager. A number of factors determined by managers, such as pay increases and promotion possibilities, do influence loss rates, although these relations are not well understood. Forecasting loss rates by community, grade, and LOS is thus an important concern for manpower managers.

\section{HISTORY OF NPRDC OFFICER LOSS RATE FORECASTING}

Initially, loss rate forecasts were generated from veighted averages of historical rates. Bres and Rowe (1979) compared the performance of several simple alternative univariate models using data from 1969-1977. Their study focused only on the one year forecast horizon. Forecast accuracy was judged on a mean absoiute error (MAE) criterion. In comparing model performance, varying lengths of out-of-sample periods were used depending on the number of lags used in estimating the model. Consequently, the resulting model performance measures are not really comparable across the different models. Nevertheless, Bres and Rowe (1979) concluded that a third order autoregressive Minimum Absolute Deviation (MAD) model could conveniently be used in all cases 
with little loss of accuracy. Given the model selection criterion, MAE, it is not surprising that a minimum absolute deviation model was chosen over a minimum squared deviation model. In Section 3 we discuss the importance of the model selection criteria.

Next, NPRDC expanded the collection of forecasting models to include a Cost of Leaving (COL) model, which was later revised to an ACOL model. Unfortunately, little documentation exists regarding NPRDC's development and implementation of these models. However, Chipman and Mum (1978) provide some insights with their implementation of the COL model for enlisted personnel. The results indicate the effect of LOS is very important in empirically implementing a COL model. In fact, the marginal effect of COL on retention is modeled as three different values for different ranges of LOS.

Seigel (1983) introduced a particular method of combining forecasts, referred to as a wear-off function. The basic idea was to generate seven successive year forecasts as a weighted average of the long term average loss rate and another method, such as the ACOL model. The weighting scheme was developed so that the longer term forecasts tended back to the long term average. A major use If this method was to extrapolate a one year forecast over the seven year horizon into successive annual forecasts. The introduction of this wear-off function yielded a new variation of the three existing methods.

A 1986 NPRDC study analyzed the forecasting performance of six different models: the three models, "no change", weighted average, and ACOL with and without wear-off. The three-lag MAD model was not examined due to the extremely limited degrees of freedom. The one step ACOL forecast was used for all seven forecast periods both with and without the wear-off function. Two different model criteria were employed, weighted absolute error (WAE) and weighted mean square error (WMSE). The weights were used to aggregate overall performance across community, grade and LOS into one measure. The results suggested that ACOL without wear-off is best with a WAE 
criteria, whereas the weighted average method without wear-off is best with a WMSE criteria. However, it is questionable whether the differences in these measures are very significant. It is surprising that a one year forecast with no future dynamics would out periorm a wear-off version which is incorporating a simple dynamic process.

The current version of the officer forecasting module uses the wear-off method to extrapolate a one year ACOL forecast to the seven year horizon when insufficient user inputs are supplied. 


\section{APPROACH TO MODEL SELECTION}

\subsection{SUMMARY}

Navy managers require forecasted loss rates to generate force strength forecasts. These forecasts are used to determine whether particular force goals can be obtained, as well as to examine a variety of what-if simulation questions. Currently, loss rate forecasts are generated with both dataand theory-based models depending on the policy question of iuserest. The data-based models are based solely on the past retention rates of the particular grade/LOS retention rate being modelled. The theory-based model is an extended version of the ACOL model, incorporating a function of LOS. An examination of these approaches raises a variety of issues regarding model selection and implementation which are discussed in the following sections.

A major missing link in current NPRDC manpower projects is relating the uncertainty in forecasting loss rates to the resulting conclusions regarding manpower strength. The variance of the estimated loss rates could, for example, be used to construct confidence intervals around force projections. The probability of achieving a desired manpower goal would then reflect the underlying uncertainty in loss rate estimates.

\subsection{MODEILNG OBJECTIVE: FORECASTING VS SIMULATION}

Before choosing a modelling approach to analyze personnel retention, a clear statement of objectives is necessary. The class of models of interest, if the two major concerns are forecast accuracy and minimizing operational costs, will differ substantially from the class of models dictated by concerns for policy simulation as well. Both data-based and theory-based models are of interest with a forecasting objective, whereas, only theory-based methods are relevant when policy simulation is also an objective. The range of theory-based models can be reduced further depending on the policy questions of interest. 


\subsection{FORECASTING OBJECTIVE}

The relative forecasting ability of these models will depend strongly on the forecast horizon length. Typically, data-based methods outperform theory-based methods for short term projections. However, a "good" theory-based model is usually preferable in predicting turning points and long term trends. A pragmatic compromise is the combining forecast methodology suggested by Granger (1969, 1974, and 1984), in which the individual period forecasts are combined with weights that vary with the forecast horizon. In combining forecasts, the empirically estimated weights will most likely increase for the theory-based models relative to data-based models with the forecast length horizon.

An important issue in evaluating a model's forecasting ability is in choosing a suitable measure of forecasting accuracy. Ideally, the end use of these forecasts should have some bearing on the choice of forecasting criteria. A decision theoretic approach implies that the optimal model choice sh ' $\mathrm{d}$ minimize the cost of being wrong. The appropriate forecasting criteria is then a "loss function" which associates a particular cost to all possible forecast errors. If the loss function is asymmetric, then most measures typically employed, such as the root mean square error (RMSE) or mean absolute error (MAE), would not be appropriate. In practice, it is usually difficult to exactly specify this loss function. The cost of surplus manpower could in principle be calculated based on a plan to reduce the force to desired levels; however, the cost of a manpower shortage may be difficult to quantify. However, some consideration of the loss function is helpful in specifying what general properties, such as symmetry or derivative restrictions, the forecasting criteria should possess. For example, the question of MAE versus MSE can be viewed as a second derivative restriction. A MAE criterion implies a linear loss function as compared to a concave function implied by a MSE criterion. It seems likely that NPRDC's loss function is nonlinear in that the cost of one large error may be greater than the summed cost of a series of small errors, in which case the MSE criteria is more appropriate than MAE. 
The cost of up-dating and maintaining a forecasting system is likely to be an imporiant factor in selecting a modelling approach. Theory-based approaches such as ACOL or DRM are expensive to update becaus : of the extensive data inputs. Similarly, the cost of updatıng may limit the degree of disaggregated modelling with data-based methods. For example, in examining a variety of databased niethods Rowe (1979) focuses on choosing one technique to be used for all forecasts to reduce complexity and data processing costs. This all-purpose model constraint conflicts with the basic model selection process recommended for univariate models. The recommended procedure consists of three phases: identification, estimation, and diagnostic checking. This process is discussed in more detail in section 4 .

A major limitation in developing forecasting models is the limited time series available, i.e., for 1974 through 1986. Many of the data-based methods require a reasonably long time series to be worthwhile. Sufficieni data must be available to reserve out-of-sample periods, include all important piedictive variables, and have an error teim with sizable degrees of freedom relative to the total number of predictive variables.

\subsection{SIMULATION OBIECTTVE: THEORETICAL VS EMIPIRICAL}

A spectrum of theory-based models can be thought of, depending on the degree of model detail. The set of assumptions underlying each model determines which policy simulation issues can be addressed. Models that depend on the existing compensation and personnel policy structures do not permit examination of changes in these structures. Inference regarding some policy issues may be made directly from past experiences with simple descriptive models. Whereas, other issues may require a fairly complex behavioral model to deduce the possible net effect.

NPRDC has indicated that the following priority be assigned to policy simulation issues for analysis of officer retention:

1. Regular Military Compensation (RMC)

2. Lump-sum bonuses

3. Special Pay Increases

4. Retirement benefits. 
The first three issues are treated together here under the general heading of current compensation as opposed to the fourth item which is clearly of a different nature. Current compensation issues are discussed separately in Section 5.

The range of simulation questions that can be addressed by the simpler descriptive models is limited by the range of variation in the sample data set for which the model is estimated. Unfortunately, the historical variation in real compensation since 1974 has not been very large. Real annual regular military compensation has varied approximately between plus or minus $6 \%$. Bonuses and special pay which have been applied to select occupations could have increased real wages by as much as 10 or 12 percent, as long as the imposed congressional ceiling is not encountered. Retirement benefits, on the other hand have changed very little since 1974.

Compensation prediction can to some degree be validated by out-of-sample comparisons. Model predictions for retirement issues, however, cannot be validated by historical experiences with the limited variation in the historical data and length time series. Support for accuracy and reasonableness of model predictions will depend on common sense appeal and strength of theoretical structure.

\subsection{MODEL SEILCTION}

A central issue among econometricians is improving the credibility of econometric results. In accomplishing this goal a general methodology consisting of three basic modelling phases is recommended:
A. Selection of a general model,
B. Explanation of how and why any general model was simplified to the preferred one(s), and
C. Quality control of the preferred model(s). 
Typically, the quality control phase is given limited attention or ignored completely. Realization of this shortcoming has stimulated the development of criteria for the formal evaluation of models. The outcome of this research can be usefully categorized as:

1. Consistency with theory;

2. Significance, both statistical and economic;

3. Indexes of inadequacy;

4. Fragility or sensitivity; and

5. Ability of the model to encompass or reconcile previous research.

Categories 1 and 2 have been a major concern in past valuative analysis. Category 3 has recently gained increased attention with the formulation of a variety of diagnostic tests. Hendry (1980) provides a general perspective with a detailed application presented in Hendrv (1983). The fourth item focuses on how sensitive key parameters of interest are to variations in model specification. Alternatively, new data may be used to assess a model's fragility. This is done either through predictive failure, recursive estimation, or interaction with other parts of a model as in simulation analysis. The final category requires that a well-specified model be able to explain the performance of competing models. Lack of reconciliation between studies is a major deficiency of much current applied work.

These considerations are particularly important when the relevant theory is insufficient to guide empirical investigations. The various applications of ACOL provides a good example of this situation. The presentation of these estimated models provide no indication of how the reported specification was arrived at. Consequently no two estimated models are reported with the same specification. Similarly, the quality control items 3-5 were generally not applied. 


\section{ALTERNATIVE MODELING DIRECTIONS: FOR RETIREMENT}

In this section three different general objectives are considered: simulating retirement issues, simulating compensation issues, and forecasting manpower availability. The objectives are ordered in this way so that the discussion proceeds from the theoretical to the empirical models and issues.

A detailed model of officer retention is required to examine alternative retirement policies. Two competing models for such analysis are ACOL and DRM.

\subsection{MODEL STRUCTURE OF ACOL VS DRM}

Both DRM and ACOL model individual retention decisions as an optimization process subject to a series of simplifying assumptions regarding behavior and information. The DRM carries the maximizing paradigm considerably further. The two major extensions incorporated in the DRM are future uncertainty and persistent taste for the service. Additional DRM equations are in Section 2.1.4. Each period, the stay/leave decision in the DRM is based on the sum of the expected cost of leaving, $c_{\mathrm{b}}$ and a random shock, $e_{k v}$ experienced in the current period t. The expected cost of leaving is a function of the expected pecuniary returns from both staying and leaving, as well as an individual constant taste for the service, $\phi_{k}$. This expected cost can be written as the difference in the expected returns from staying and leaving,

$$
C_{i}\left(i, \phi_{k}\right)=M_{k,}-L_{i},
$$

where $\mathrm{M}_{k, i}$ and $\mathrm{L}_{\mathrm{i}}$ are defined by (2.16) and (2.14), respectively. The decision to stay requires that

$$
e_{k}+C_{1}\left(i, \phi_{k}\right)>0
$$

for officer $\mathrm{k}$ in state $\mathrm{i}$ and period $\mathrm{t}$. Random shocks, such as a death in the family, are assumed in the DRM to occur exogenously each period. The recursive form of $c_{t}$ due to the element of future uncertainty and the control theoretic approach of the DRM does not permit a separation of the taste and pecuniary elements. Let $S_{1}(i)$ denote a stay decision when occupying state $i$ in period $t$. The 
probability of observing the sequence of stay/leave decisions may be written as

$$
\operatorname{Pr}\left[S_{i}(i), \ldots, S_{t+n}(j)\right] \quad=\int_{-\infty}^{\infty} \int_{-c_{i}\left(i, \phi_{k}\right)}^{\infty} d F(e) \ldots \int_{-c_{t+n}\left(j, \phi_{k}\right)}^{\infty} d F(e) g\left(\phi_{k}\right) d \phi_{k},
$$

where $g\left(\phi_{k}\right)$ is the density function for tastes, and $F(e)$ is the cumulative distribution function of the random shock.

The resulting model yields a censcring process with the average taste for the service increasing over time. This is an important factor not captured by ACOL. Both Gotz and McCall (1984) and $\operatorname{Ar}$ guden (1986) point out the internally inconsistent treatment of taste for the service in the ACOL model as described by Enns, Nelson, and Warner (1984). On the one hand, taste for the service is assumed constant in the calculation of the annualized cost of leaving. On the other hand, tastes are assumed identically, independently, and logistically distributed over time and across individuals.

The ACOL model can be represented using equation (4.2) by dropping the random shock term and all notion of future uncertainty. Thus, the form of $c_{1}$ can be simplified because the optimal career length $\mathrm{m}$ can be determined with a completely deterministic future. The result is that the effect of the taste and pecuniary elements can be separated as

$$
\theta_{k} \sum_{i=1}^{m} \beta^{i}+P V C O L>0
$$

where $B$ is a discount factor and PVCOL is the present value cost of leaving, which is a function only of military and civilian pay and $B$.

The probability of observing the sequence of stay/leave decisions may then be written as

$$
\operatorname{Pr}\left[S_{1}(i), \ldots, S_{l+m}(j)\right]=\int_{-\operatorname{col}_{t}(i)}^{\infty} g\left(\phi_{k}\right) d \phi_{k} \ldots \int_{-a c o l}^{\infty} g\left(\phi_{k}\right) d \phi_{k},
$$


where

$$
\operatorname{acol}(i)=\operatorname{PVCOL} /\left(\sum_{i=1}^{m} \beta^{i}\right) .
$$

The resulting model does not reflect the effect of length of service (LOS) on retention rates due to a higher average taste for the service. Noting this fact, both Warner and Arguden have suggested including some function of LOS as an "ad hoc" extension to the ACOL model. Interest in polity simulation raises the question of whether these extensions are invariant to changes in compensation or promotion schedules. Implicitly, the inclusion of functions of LOS captures the effect of a rising average taste for the service over time as officers with low tastes leave the service. Policies which affect the rate at which the average taste for service increases with time are, therefore, not invariant to policies. Simulating such policies with an extended ACOL model will only yield the partial effect from changes in the ACOL variab's. The total effect can not be determined without assessing how the average taste for the service is affected.

A comparison of equations (4.3) and (4.4) indicates a fundamental difference in the models. The DRM models an officer's entire career in a way that the sequence of stay/leave decisions are considered jointly in estimating the underlying taste parameter. In contrast, the ACOL model treats the sequence of stay/leave decisions independently.

Gotz and McCall (1984) provide some evidence that the DRM fits data for Air Force officers better than either ACOL or PVCOL. However, the extended ACOL models were not examined in this comparison of models. Given the typical loss rate profile as a function of LOS, it is not surprising that either ACOL or PVCOL fit poorly.

\subsection{SIMULATION PERFORMANCE}

The modeling of future return as certain or uncertain is a major determinant of the model's simulation predictions. When there is no future uncertainty - as with ACOL - the optimal career length $\mathrm{m}$ can be calculated as a first step in determining the annual cost of leaving. Thus, policy 
measures which only have an effect after career length $m$ have no effect on the annual cost of leaving and in turn no effect on retention. Similarly, only the most likely promotion path in ACOL is used in calculating the annualized cost of leaving. Thus, many changes in $\mathrm{pr}^{\prime}$ motion probabilities will have no effect on predicted retention. Likewise in the ACOL approach, changes in the current fail-select policy will have no effect on retention. The modeling of uncertainty also affects the time value of money. The current compensation equivalent of future discounted expected return is generally less than that of simply discounted future returns. This point is of particular interest in examining policy issues such as the efficiency of lump-sum payments over installment payments. The ACOL model is indifferent between the two different methods of payment as long as the present value is the same discount rate used in the ACOL model. In the same situation, however, the DRM model would always prefer the lump-sum method of payment.

Arguden provides some evidence that the simulation prediction of ACOL type models is poor, particularly for mid-career decisions. The ACOL model is examined using a Monte Carlo methodology which assumes the real world is accuratel.' modeled by the DRM. If we believe the model structure of the DRM, then Arguden'- result provides some indication of the cost in accuracy of using simpler models, such as the extended ACOL models.

\subsection{DATA REQUIREMENTS}

The DRM requires all the data inputs of ACOL, such as detailed civilian and military earnings, but also requires longitudinal data of stay/leave decisions and promotion probabilities. The ACOL model, however, can be estimated using either grouped or longitudinal data. Civilian earnings are typically estimated using Current Population Survey estimates. This approach requires that a potential civilian occupation be identified to infer civilian earnings from an age-earnings profile. A simpler and more accurate approach might be to use the DOD/IRS data base described in Fifth Quadrennial Review o. Military Compensation (referred to as "Fifth Quadrennial Report") to track civilian cohorts. Currently this data set is updated through 1984. A new update is being considered 
tentatively for the fall of 1987 . The major limitation of this data set is the cell format used to mainiain confidentiality. The cell definitions impose a fair amount of aggregation on the data. The rest of this section discusses some of the details in using the DOD/IRS data base and provides some recommendations for assessing the usefulness of this data base for the updated officer retention rate models.

As noted in the Fifth Quadrennial report, in order to assess the proper relationship between military officer and civilian earnings, it is necessary to compare similar groups of officers and civilians. If no carefully thought out matching is made between the two groups, then the estimated civilian earnings might very well be overstated. The analysis for 1980 data described in the Fifth Quadrennial report recommends that matching variables include those which describe personal preferences related to work, mental characteristics, sex, age, and education. The report was able to make some match on mental and physical aspects by only including in the matching those men (insufficient data was available for females) who were veterans and had, therefore, passed the same military mental and physical screening tests.

Cross tabulations showed that officers (with the exception of those with less than 12 years of education) earned about the same as their census peers with similar levels of education. Average earnings of full time officers were $34 \%$ higher than the average full time earnings of census veterans. Overall, retirees showed lower relative average incomes than separatees. Many other observations appear in the report.

The model which estimates post-service earnings is a four stage process as follows:

1. Stage one: Estimate full-time veteran earnings (for maies earning $\geq \$ 6000$ ) from census data using this equation:

$$
\text { Earnings }=\alpha+B_{1} \text { age }+B_{2} \text { age }^{2}+B_{3} \text { race }+B_{4} \text { education }+e
$$

2. Stage two: Calculate imputed civilian earnings for separatees and retirees using the equation from stage one. 
3. Stage three: Calculate the post-service earnings differentiais, i.e., separatees' and retirees' actual eas nings minus imputed earnings.

4. Stage four: Estimate earnings differentials as a function of separatees' and retirees' personal military attributes.

Variables used in the regression equations include:

$\operatorname{LOS}(\leq 5 \mathrm{yrs})$,

LOS (6-9 yrs),

LOS (10-13 yrs),

LOS (14-17 yrs),

Education ( $\leq 12 \mathrm{yrs}$ ),

Education (12-15 yrs),

\{Time since separation (0-1 yrs); (2-3 yrs), and (4-6 yrs), \}, \{Years in last grade - mean time in last grade\},

race,

\{Pay grade 1:0-5 and above for LOS $\leq 17\}$, and

\{Pay grade 2:0-5 and above for LOS $\geq 17\}$.

The study includes analyses for all officers, all enlisted, officers by twelve occupation categories, and enlisted ty twelve occupation categories. The matching of the military and civilian occupations is based on a Booz, Alltn, and Hamilton study," Military Crosscode Project," and the DOD Occupatione' Conversion Manual.

The Fifth Quadrennial study was carefully completed and documented in 1984 . Additional work has been completed at other institutions in the United States, and more current results may be available (although 1984 is relatively current.). The Fifth Quadrennial study is based on 1980 data, but the current data base has been updated for 1984 . The data is free and available immediately. At least for a few critical occupations, this data and methodology for estimating civilian earnings should be compared to the Current Population Survey (CPS) data and N.PRDC calculations. The impact on the ACOL results because of the differerses in the two data/estimation procedures should be assessed, at least for a few critical occupations. It is expected that the DOF/iRS data base will provide accurate salaries and a better match for estimating potential civilian earnings for military retirees and separatees. This should be true, particularly because the IRS/DOD data base can 
provide salaries for the special subset of civilians with military backgrounds instead of all civilians, as the CPS does.

One final note concerning the data to be used and the estimation procedures considers an historical tracking and analysis of errors in the forecasted retention rates. Such an analysis should show which occupations are frequently over-or under-estimated, if any. Analysis of these trends may indicate other components of manpower planning which should be estimated separately or included in the updated model(s).

\subsection{EXTENSIONS TO CURRENT DRM}

Additionai information regarding individual taste for the service should be included, such as the extent of sea duty. Previous studies of enlisted retention, Warner (1982), show that sea duty, marriage, and race are important determinants of the enlisted loss rate.

Similarly, information such as the unemploynent rate should be included to indicate the probability of getting a civilian job. Both the DRM and ACOL assume the individual can obtain a civilian job with certainty at the going wage. One question is whether post-service civilian employment should be modeled with uncertainty with, for example, the associated probability a function of the unemployment rate or with the unemployment rate entered as a separate factor.

The discount rate should be estimated jointly with the other parameters of the model. Alternatively, an age-specific discount rate should be used to reflect the higher discount rate of young officers. For critical occupations, the continuum of extension decisions confronting a Navy officer is not modelled in the current DRM. Incorporating a selection of different length commitments is a necessary feature for examining retention issues in these critical occupations.

Previously Gotz and McCall (1983) developed a formulation of the DRM which incorporated constant absolute risk-aversion. This model was not utilized in later analysis of Air Force officer retention. It would be of interest to know why this extended DRM was not employed. 


\subsection{COMPUTATIONAL ISSUES WITH CURRENT DRM IMPLEMENTATION}

Estimation of the standard deviation of the random shock $\sigma_{e}$ complicates the problem of maximizing the likelihood function. The expected cost of leaving $c_{t}$ defined by (4.1), which appears as a limit of integration in (4.3) must be evaluated as a dynamic optimization process for each value of $\sigma_{e}$. In the current implementation of the DRM the likelihood function is maximized by searching a range of $\sigma_{e}$ values. For a given $\sigma_{e}$ value the likelihood function is maximized with respect to the other parameters. The estimated value is then chosen as the maximum of the conditional likelihood values.

Unfortunately, unless this procedure is iterated there is no guarantee that the resulting estimates are the maximum likelihood ones. A related problem is calculating the standard error of the parameter estimates. In general, unless the information matrix is block diagonal, the above twostep procedure will not yield correct estimates of the parameter standard errors. Currently, the procedure does not even calculate a second derivative of the conditional likelihood function to approximate the standard error of the estimated $\sigma_{e}$. Such estimates would be useful in determining how important this parameter is, which is of particular interest due to the computation costs. In practice Gotz and McCall minimize this computational difficulty in part by pooling estimates of $\sigma_{e}$.

\subsection{ADDITIONAL INFORMATION OF INTEREST}

The DRM is not currently being used by any branch of the armed services; but, the Air Force is now expressing new interest.

\subsection{SUMMARY}

The DRM is the best (in terms of theoretic development) of existing retention models (PVCOL, PPM, ACOL) for policy simulation of retirement issues. However, the current formulation and implementation of the DRM still leaves much room for improvement. Application to all Navy occupations scems impractical because of data and computational requirements. Application to a few 
key occupations is a reasonable approach to analyze policy issues, such as retirement benefits. A considerable effort would be required to implement the current version of DRM for efficient and flexible policy analysis usage. In addition, the model should be extended to incorporate more information regarding an individual's taste for the service. The important question is how cost effective the current version of DRM is, as well as the above suggested additions. 


\section{ALTERNATIVE MODELING DIRECTIONS: FORECASTING FOR COMPENSATION}

\subsection{SIMULATING CHANGES IN CURRENT COMPENSATION}

In this section we shall consider compensation policy issues which include RMC, lump-sum bonuses, and special pay increases. As before, we focus on the two models ACOL and DRM.

\subsubsection{Regular Military Compensation, RMC}

Both ACDL and DRM could be employed to analyze changes in RMC. From the above discussion regarding ACOL it is clear that an extended version which included a function of LOS would be required. Omission of this extension would cause ACOL to overvalue the returns to staying for mid-career officers.

The relative performance of these models is an empirical question in that the extended ACOL model may provide a suitable approximation. Because historical real changes in RMC have been less than 5 or 6 percent, it may be reasonable to limit analysis of proposed changes to a similar magnitude. An important question raised already is whether the parameterization of this extension is invariant to the policy questions of interest.

A second concern in simulating changes in RMC is specifying at what point such changes are anticipated by officers. The effect on predicted retention rates will vary substantially depending on whether and how long RMC changes are expected in advance.

\subsection{Lump-sum Bonus}

Bonus payments, either lump-sum or installment, are usually employed to obtain a longer term commitment for critical occupations, such as nuclear submarine officers. Sometimes a range of commitments for continued service is available. Unfortunately, the effect of such bonuses on officers is virtuary unknown compared to the attention devoted to enlisted personnel. 
In modelling second term enlistment rates Warner (1979) notes the importance of first term bonuses. He hypothesizes that a negative effect will occur because an individual with low taste for the service and who was retained previously due to a bonus will leave without further incentive to stay. This effect tends to be confirmed by the data. It follows that the same problem would occur in applying the ACOL model to officers over a range of LOS; then, the ACOL specification should include lagged bonus payments in addition to LOS terms.

Allowing a range of commitments in modelling officer retention complicates the problem of identifying that population making a career decision at any point in time. The difficulties in incorporating this extension in the DRM are considerably greater than for the ACOL model.

Alternatively, Gotz and McCall (1984) consider the effect on retention of a lump-sum bonus paid at a particular length of service. The DRM simulation results show retention rates increasing for those officers with less than the required bonus LCU as they look forward in anticipation of receiving the bonus. Retention rates then drop as officers pass the required bonus LOS.

\subsection{Special Pay Increases}

Special pay has been allotted to a variety of select occupations. These additional payments are sometimes similar to bonuses in that they offer an inducement for a longer term commitment. Thus, the amount of special pay is determined as a function of the commitment length. As mentioned previously, bo in ACOL and DRM only model a simple stay/leave decision, as opposed to a variety of alternative commitments. Additional modelling would be required to handle such alternatives.

Special pay is also sometimes allocated simply as a fixed amount, and the range of real pay increases for special pay is somewhat larger than for RMC. Special pay and RMC can both be modelled with ACOL. 


\subsection{ALTERNATTVE MODEL FEATURES}

Ideally, one would like to examine a whole class of models which incorporate the important features of proposed retention models such that a series of nested hypothesis tests would yield a particular model which best describes the data. Since ACOL and DRM differ in several basic ways the importance of individual features is not apparent from a simple comparison of model fit.

These features may be described as:

a. Expectation formation: Is the DRM control theoretic formulation necessary, or is the simpler form of ACOL sufficient, or should we have more detail yet? For example, civilian employment could be modeled as uncertain with the associated probability of employment a function of the unemployment rate.

b. Censoring effect: Constant or persistent taste for the service implies that the average taste for service is increasing over time. How important is this factor? Does incorporating a function of LOS provide an adequate approximation?

c. Future uncertainty: If a random shock occurs each period, it would be inconsistent to assume officers do not take into account future shocks. The question is should this be incorporated in an optimal sense as in the DRM or in a more ad hoc fashion such as adopting a higher discount rate. A major portion of DRM computational cost is due to the future uncertainty parameter. Also, how much of the variation in retention is accounted for by variations in future shock?

d. Additional information: How important are the above considerations relative to the importance of including general information, such as the unemployment rate, or specific demographic and career information.

By considering the various combinations of these features we can construct a variety of retention models. One possible model is an ACOL model of the officer's career based on an assumption of constant taste for the service.

\subsection{FORECASTING ISSUES: SHORT-TERM AND MIDTERM MANPOWER AVAILABILTTY}

The DRM and similar models are clearly not cost effective forecasting tools for day-to-day use, particularly for the wide range of occupations which must be addressed. The costs of maintaining and updating the forecasting procedures, as well as the forecasting accuracy, are the major concerns. 
We assume in the following section that the model selection issue has been satisfactorily addressed at this point. The models considered in this section are roughly ordered by relative cost.

\section{S.4 UNTVARIATE MODELS}

The length of the available time series is an important limiting factor. Previously Bres and Rowe (1979) compared a variety of univariate models in forecasting loss rates by community/grade/LOS. Only nine annual observations (1969-1978) were available for this study. Consequently, some of the estimated models in this study have zero degrees of freedom. Unfortunately, eight years later, only thirteen annual observations (1974-1986) are available because the data quality of the 1969-1973 observations is considered unacceptable. Model selection based on out-of-sample forecast performance requires that some observations be withheld in the estimation phase. The limited number of observations require that the number of estimated parameters be balanced against the number of out-of-sample observations. If for example, five out-of-sample years are used, a four-parameter model, such as a third order autoregressive with a constant term, would have only four degrees of freedom. The five out-of-sample years allows five observations on the performance of a rolling one year forecast or one observation on the five year forecast.

The large number of rommunity/grade/LOS forecasts required makes cost considerations a major factor. In response to this factor Bres and Rowe (1979) attempted to find one all-purpose model specification based on the one-year forecast performance. However, the recommended procedure for selecting univariate models consists of three phases: identification, estimation, and diagnostic checking. The identification phase requires that likely model specifications be chosen based on the correlation structure of the data, as revealed by the autocorrelation and partial autocorrelation coefficients of the data as well as difference transformations of the data. The estimation stage then provides an indication of whether the model parameter estimates are significantly different from zero. The final phase, diagnostic checking, consists of examining the 
residuals of the estimated models. The residuals of a satisfactory model should not show a significant correlation structure. Appropriate goodness of fit tests should also be performed. A guiding principle in this model selection procedure is to choose the more parsimonious parameter representation whenever possible. The recommended procedure for selecting univariate models is clearly very labor intensive when considering the number of required equations. Alternatively, a number of automated model selection procedures have been suggested. In ge $\mathrm{i}_{i} \mathrm{eral}$, experienced practitioners tend to out perform such automated methods, which usually choose a more parameterized model. Nevertheless, automated procedures may provide the desired compromise between cost and forecast accuracy.

\subsection{MULTIVARIATE MODELS}

Cross-sectional relations provide an interesting potential for expanding the univariate specification. Both common or cross equation effects are possible. Common effects within a community, grade, or LOS are possible in the specification of either the mean or variance. Estimating such effects requires pooling the data. The most likely candidate is the variance specification referred to as the Seemingly Unrelated Regression (SUR) system. Common effects in the mean would depend more on the individual equation specification. Such an effect seems unlikely unless all equations have the same form.

Cross equation effects may also be present in that the loss rate of a given LOS could be correlated with other lagged loss rates, such as of the previous LOS. If, for example, a given cohort group had an unusually high loss rate one period, we might anticipate a lower loss rate the following period in that individuals with a low taste for the service have already left. Unfortunately, modelling questions of this type must be addressed empirically. The limited available time series constrains such inquiries, because the inquiries increase the number of model parameters. 


\subsection{ECONOMETRIC MODELS}

The introduction of additional information greatly increases the modelling possibilities. A variety of transfer function type models may prove useful. For example, these models may include both military and civilian earnings and the unemployment rate, as well as a Box-Jenkins specification of the error term. The previous studies of enlisted personnel suggest several other demographic and career variables.

The above issue of common or cross equation effects is also of interest here. The previous ACOL models all imposed a number of common parameter restrictions for both the constant and slope term in pooling across grade and LOS as well as cominunities and branches of the service. Statistical tests of these restrictions, however, are not reported.

The specification of these models is an iterative procedure utilizing a battery of diagnostic tests as quality control measures. As a result of this evaluation process the proposed specification is either accepted or revised, continuing the specification process.

\subsection{COMBINING FORECASTS FOR A GIVEN LENGTH FORECAST HORIZON}

A combined forecast approach, as suggested by Granger and Ramanathan (1984), is likely to yield the most accurate forecasts for the required range of forecast horizons, which is one to seven years. This approach allows the data to determine the relative value of different forecast models for a given length forecast horizon. Ideally forecast weights should be chosen for each length forecast horizon so as to minimize the corresponding forecast error variance for that length forecast horizon. Again, a major drawback of this approach is the limited available time series. Estimating the combining weights requires a reasonable length out-of-sample period. 


\section{SUMMARY AND CONCLUSIONS}

\subsection{CONCLUSIONS RELATIVE TO THE NPRDC ENVIRONMENT}

1. NPRDC analyzes manpower policies for high-level military decision makers and has determined that the ACOL methodology, data, and model variables require updating. Loss rates are forecast by military community (occupation), grade, and LOS. The models must be able to analyze the following four policy areas:
a) Regular Military Compensation (RMC),
b) Lump sum bonuses,
c) Special pay increases, and
d) Retirement benefits.

2. The following information on the NPRDC policy areas should help guide the model selection:

a) There is little variation ( $s 6 \%$ ) in RCM and none with respect to retirement.

b) Special pay data have shown the most variation.

c) Retirement issues cannot be validated by historical experiences and, therefore, will reouire simulation models.

d) RCM and special pay can both be handled with the ACOL model, but bonus and retirement pay analyses should use the DRM.

3. Investigating the history of military retention modeling has been instructive and has provided insight on methods and variables which did not have potential. Some highlights of the conclusions from the various studies; appear in Table 1 along with other summary information obtained during the subject area investigation.

4. While several references appear in Table 1, the problem of providing solutions to modeling manpower retention has by no means been exhausted. These studies have sparked several questions - enumerated in Section 5.2 - which should be considered and investigated. 


\begin{tabular}{|c|c|c|c|c|c|c|c|c|c|c|c|}
\hline \multirow{6}{*}{ 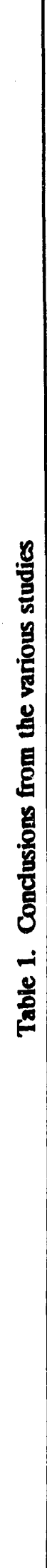 } & 胥 & 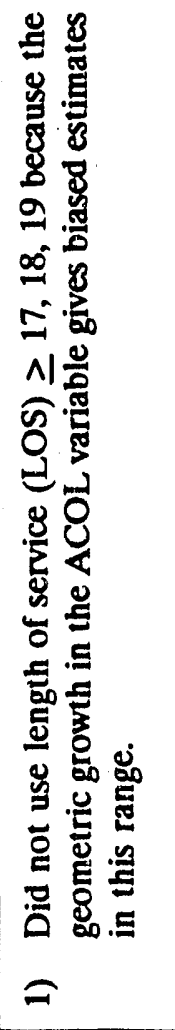 & 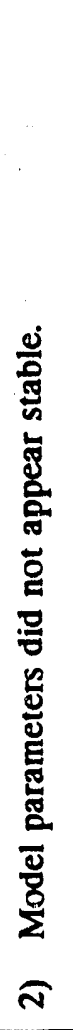 & 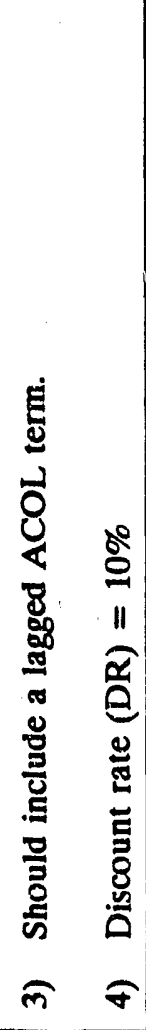 & 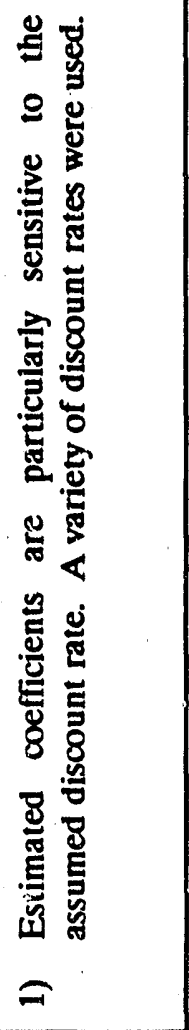 & 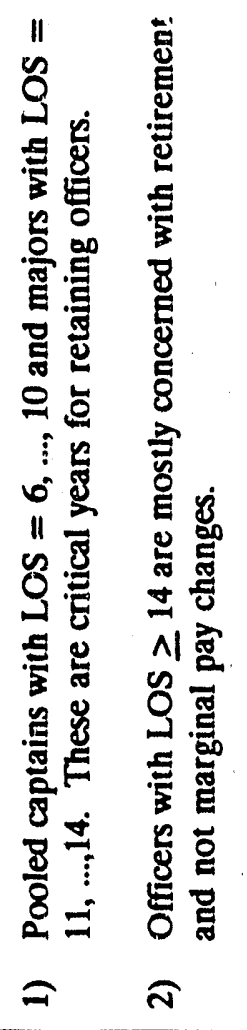 & 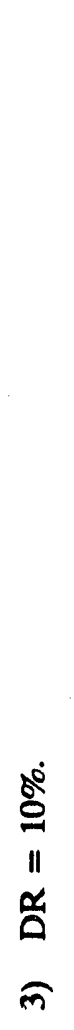 & 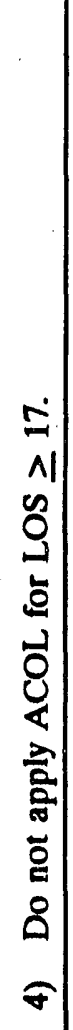 & 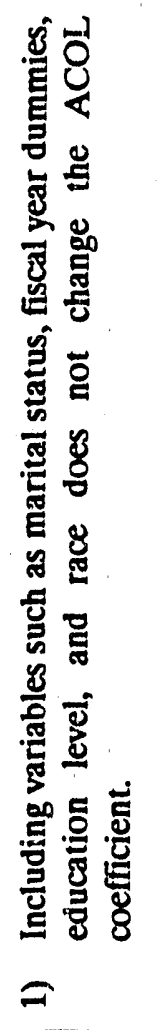 & 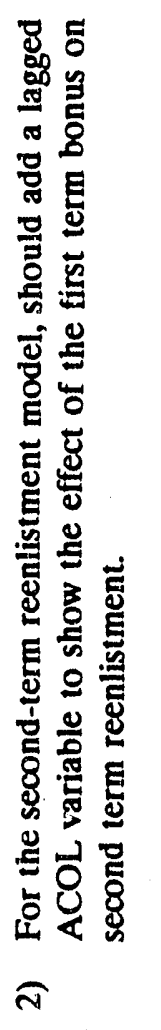 & 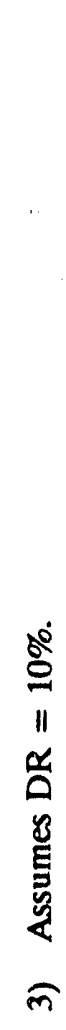 \\
\hline & 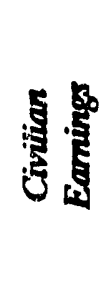 & 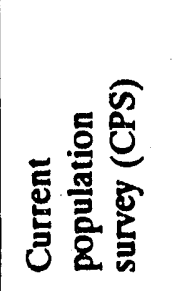 & & & 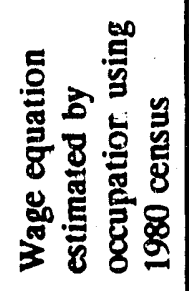 & 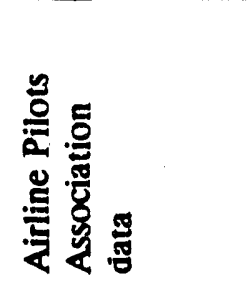 & & & 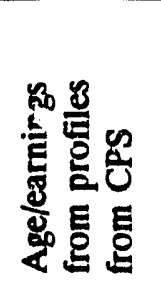 & & \\
\hline & 总 & 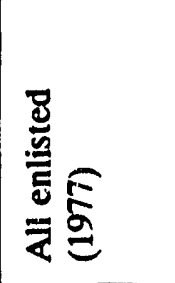 & & & 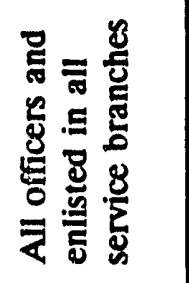 & 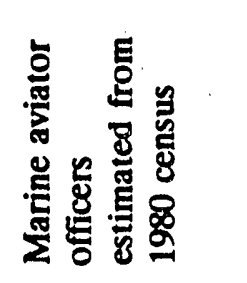 & & & 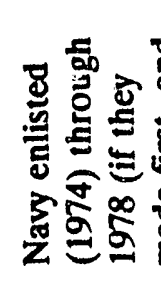 & 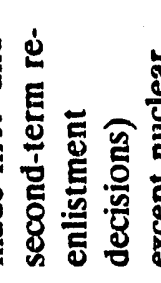 & \\
\hline & है & 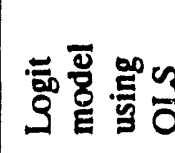 & & & 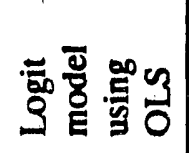 & 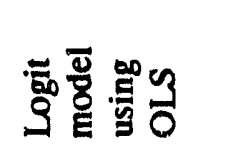 & & & 咅愛 & & \\
\hline & $\frac{\pi}{8}$ & 宅 & & & $\overrightarrow{0}$ & రి & & & 它 & & \\
\hline & 㿣 & 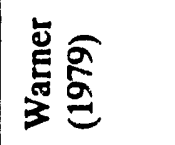 & & & 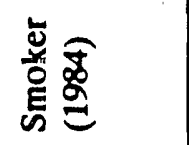 & 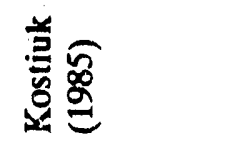 & & & 总芯 & & \\
\hline
\end{tabular}




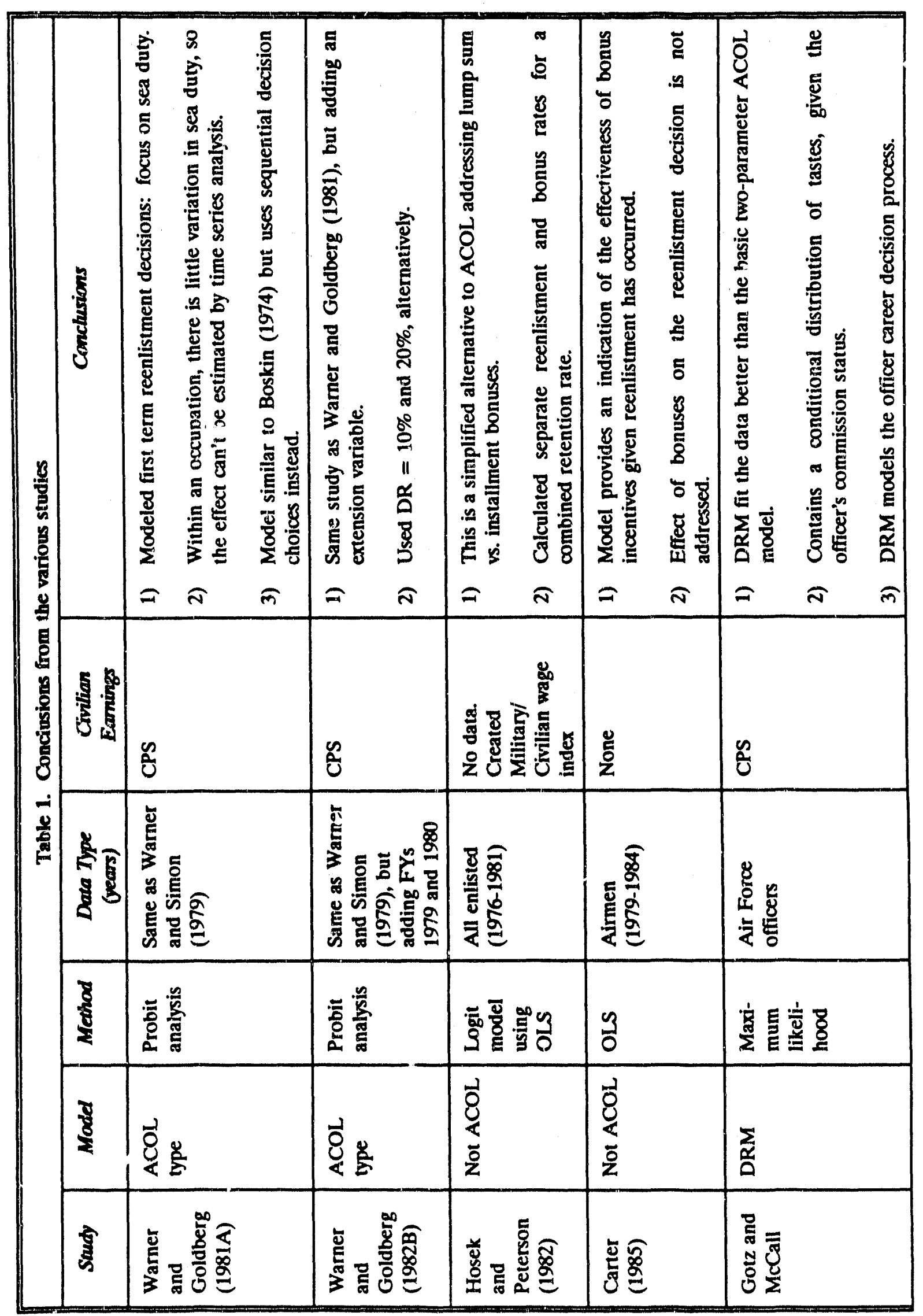




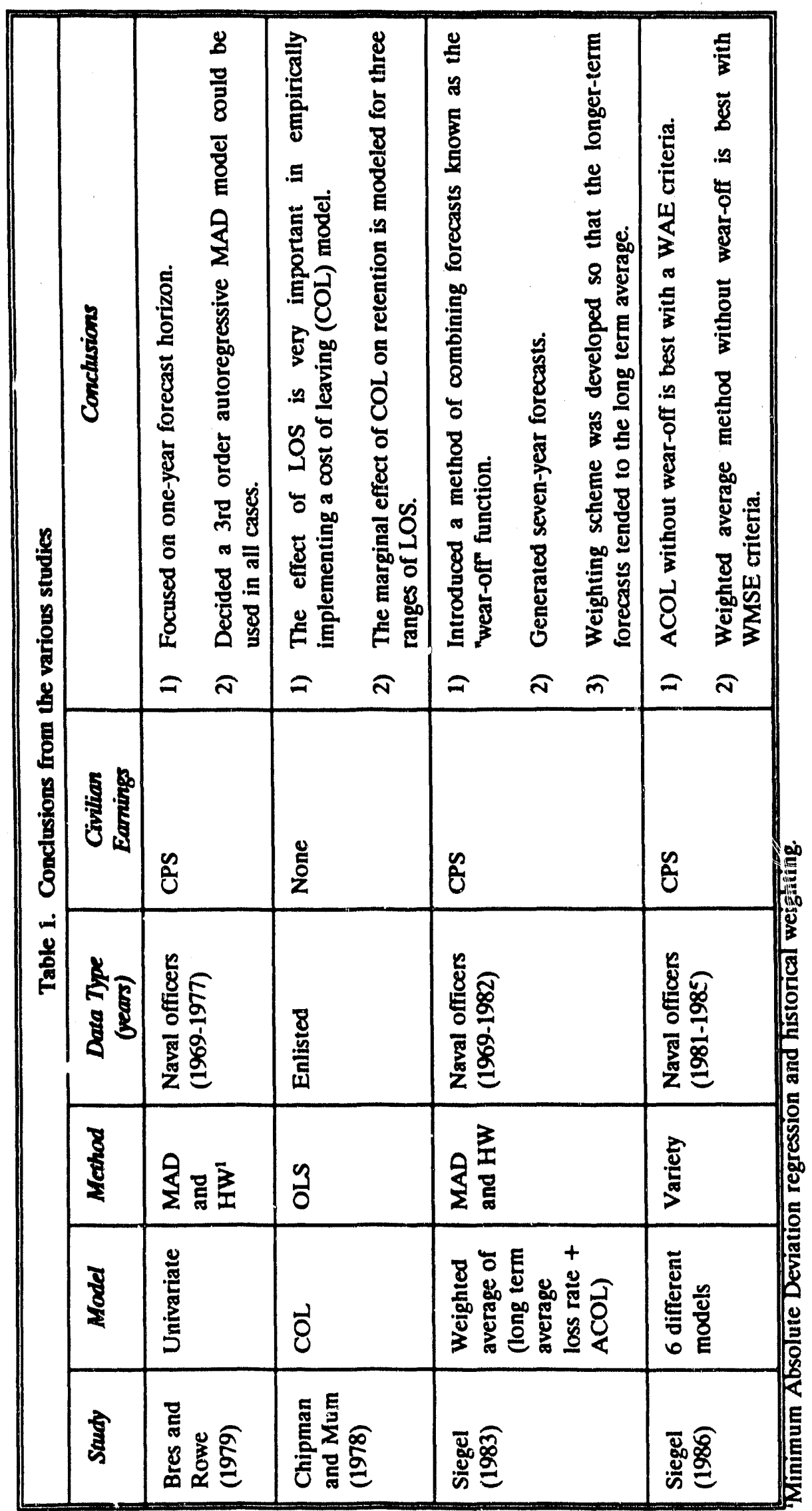




\subsection{CONCLUSIONS FOR MODEL SELECTION APPROACHES}

5. The cost of updating and maintaining a forecasting system is likely to be an important factor in selecting a modelling approach. The cost of updating the system's data base may limit the degree of disaggregated modelling with data-based methods. Also, the modelling system can be designed to take advantage of tradeoffs in computer and analyst time. An automated system can allow the analyst to interact with it and reduce the analyst's time to a decision making role. Many variations on an automated system are possible in which the system incorporates greater or fewer of the analyst's rules.

6. A major limitation in developing forecasting models is the limited time series available, i.e., for 1974 through 1986. Sufficient data must be available to (a) reserve out-of-sample periods, (b) include all important predictive variables in the equation, and (c) have an estimated model error term with reasonable degrees of freedom relative to the total number of predictive variables. Equations with additional potentially important factors cannot be tested if sufficient data (and, therefore, degrees of freedom) are not available. Finally, testing an only relatively few out-of-sample periods provides less confidence in a model's ability to predict, so the best balance possible must be struck between the three factors. The best balance is determined by the intended inference and use of the resulting model.

7. There will be tradeoffs between cost and accuracy. The simplest model that provides adequate accuracy at a reasonable cost should be chosen. However, NPRDC will need to weigh the cost of any loss in accuracy, i.e., the risk of incorrect forecasts, against the costs of a more accurate and more costly method.

8. The use of the results of the model should guide the model selection and development in order to provide accurate results and appropriate reference. See Sections 3.2 and 4. 
9. The types of models considered in this study fall in two categories, forecasting and simulation. The former can use data-based methods when (1) sufficient historical data is available and (2) the data base exhibits some variation for the predicted variable. That is, the data base must observe some change in the predicted variable in order to use forecasting methods. Typically, data-based methods are good for short-term forecasts, and theory-based methods are better for long term forecasts and simulation. Finally, data-based and theory-based methods are applicable to forecasting objectives, but only theory-based methods are relevant when policy simulation is also a question. So forecasting is based on historical data trends, and simulation asks "what if" questions.

10. With respect to model development, for any forecasting methodology, the best procedure for model selection consists of identification, estimation, and diagnostic checking. It is best to use a variety of diagnostics to determine the overall best model.

11. Models that depend on existing policy structures do not permit examination of changes in these structures. Depending on the policy issue, a simple descriptive or a complex behavioral model may be required. This concern is related to comment (12)(d). 
6.3 CONCLUSIONS FOR ALTERNATIVE MODEIING DIRECTIONS: THE ACOL MODEL VS DRM

12. The DRM represents a theory-based model while ACOL is a mixture of theory- and databased methods. DRM is intended primarily for simulation, while ACOL is used for forecasting anci simulation. The DRM is a more sophisticated simulation tool that models the dynamics of underlying taste for the service. ACOL tries to approximate these dynamics by using lagged bonus terms and LOS. The two methods are contrasted in sections 4.1 through 4.4 with the following highlights:

a) The fundamental difference in DRM and the ACOL model is that DRM models an officer's entire career and considers stay/leave decisions jointly in estimating the underlying taste parameter.

b) DRM fits the Air Force officer data better than PVCOL or ACOL, but the only comparison made did not include any of the extensions to ACOL.

c) ACOL treats the taste for service inconsistently; DRM does not (See Section 4.1).

d) ACOL reflects the effect of LOS on retention via a LOS function added as an ad hoc extension to ACOL. Similarly, lagged bonuses should also be added.

NOTE: It is likely that the extensions to ACOL are not invariant to changes in compensation or promotion schedules. Therefore, use of ACOL for simulation is questionable (see Section 41 ).

13. Ability of ACOL or DRM to evaluate priority NPRDC policies:

a) Both the extended ACOL and DRM can analyze changes in RMC.

i) Because real historical changes have only been about six percent, it may be reasonable to limit analysis of proposed changes to that amount.

ii) For simulating changes in special pay and RMC, it is important to determine how much advance notice of changes the officers have.

b) Neither the existing ACOL nor the existing DRM is appropriate for analyzing the effect of bonuses if the bonus offers a range of commitments for continued service. Both methods would need to be extended. The ACOL method has been extended trivially for enlisted men.

c) There is some issue as to whether lump sum or special pay encourages greater retention. ACOL cannot determine which is better. 
14. The DRM requires all the data inputs of ACOL, such as detailed civilian and military earnings. However, the DRM also requires longitudinal data of stay/leave decisions and promotion probabilities, but the ACOl model can be estimated using grouped or longitudinal data.

\subsection{CONCLUSIONS FOR FORECASTING ALTERNATIVES TO THE} DRM OR ACOL MODEL

15. Open question: Is longitudinal data better for forecasting? It is not obvious.

16. With respect to RCM and special pay, ACOL or a wage index model may be adequate for simulating in the historical range particularly for one time change scenarios. These methods give less confidence when examining more dynamic scenarios, such as lagging and catching up with civilian wage rate changes.

17. With respect to bonuses (lump-sum, installment, or extended commitment), the dynamics in the average taste for service requires a DRM-type model. For intertemporal tradeoffs, ACOL predictions are assumed in setting the discount rate. The DRM methodology estimates the tradeoff instead. The length of the bonus period can and should be examined. This work would represent a major model extension.

18. With respect to retirement benefits, the expectation formation is the major determinaut of the simulation effect. There is little empirical evidence in this area [see Gotz and McCall (1983)]. Intertemporal tradeoffs, especially long term, are also important for retirement policy simulation. 


\subsection{CONCLUSIONS FOR VARIABLES TO CONSIDER FOR THE UPDATED MODEL}

19. Previous studies have shown that these variables must be included in the model or should be tested:
a) LOS,
b) Lagged bonus-effect variables (for ACOL type models),
c) for pilots, the change in the number of civilian pilots,
d) civilian unemployment rate, and
e) sea duty and marital status (test).

20. The discount rate was shown to have an important effect on retention estimates and appears to be age specific. It might be best to estimate the visccunt rate jointly with other parameters.

21. Because it is difficult to determine a priori what other variables may provide some significant contribution to the variance of a predicted value, it is important to leave the variable selection decision open and let the data analysis guide the way via Sections 3.2 and 3.4 .

22. LOS rate as a function of ACOL and LOS dummies are the variables used in the NPRDC ACOL model.

6.6 CONCLUSIONS FOR ALTERNATE CIVILIAN DATA CONSIDERATIONS

23. The NPRDC's ACOL model currently uses Current Population Survey estimates. Kostiuk (1985) used Airline Pilot Association Data. Smoker (1984) used 1980 census data. Warner's studies used the Current Population Survey.

24. The Fifth Quadrennial Review of Military Compensation provides a detailed analysis of a DOD/RS data base which may provide better estimates of civilian earnings opportunities available to military retirees and separatees than the CPS currently used by NPRDC.

25. Before switching data bases, analyses should be completed for a few critical occupations (and/or those occupations whose retention has historically been over- or under-estimated) in order to assess the impact of the data on current NPRDC estimation techniques and the potential updated models. 


\section{RECOMMENDATIONS}

Suggested procedures for the two differing objectives of forecasting and simulation are discussed separately in this section. The recommendations are roughly ordered by cost, starting with the least cost items.

\section{FORECASTING}

Improving the univariate models in STRAP-O is one area likely to yield low cost forecasting improvements. Currently, STRAP-O uses one model specification for all grade/LOS cells. An automated procedure which selects a model for each cell from a class of models is likely to result in a smaller aggregate forecast error. The choice of procedure is primarily an empirical question in which the evaluation criteria is the major determinant. Consideration of the decision maker's loss function should guide the choice of evaluation criteria. The class of alternative models is limited due to the short time series available for the grouped (grade/LOS) data. The number of lags and parameters in this class of models should be limited to two or three. By automating the selection procedure, costs are limited to the major cost of initial development and the comparatively small computer cost of updating.

This first modelling approach may be improved by including additional information. The motive for doing so is the belief that a larger information set can only increase the forecasting content. Forecasting models, referred to as transfer function models, which include additional information as well as a BOX JENKINS specification of the error structure are one way of extending the models of the first stage. Variables which are likely candidates for such extensions are the unemployment rate and wage indices of civilian and military pay. Additionally, summary measures of the grade/LOS cell, such as average time remaining under obligation (TRO), may prove useful in forecasting. 
An important consideration in choosing additional information to incorporate in the forecasting model is the cost of updating. Also, the model selection process should ideally include a diagnostic phase to check the adequacy of the selected model.

Further forecasting improvements may be obtained by pooling observations on grade/LOS cells. This action is only helpful if the data does support commol' parameter restriction. The parameter restrictions should be examined and statistically tested when considering pooling. The benefits of pooling are that the limited degrees of freedom are less of a problem and the parameter estimates are more efficient (this is of more interest when simulation is the objective). In pursuing a forecasting objective, the benefit of pooling is still an empirical question.

The limited time series for the grouped data is a major restriction in considering forecasting approach. In the future, when more observations are availa'ble, additional methods should be considered. For example, an adaptive combining-forecast method using an out-of-sample evaluation period is likely to yield further forecasting improvements.

\section{SIMULATION}

Simulation questions with regard to regular military compensation and special pay are perhaps the easiest issues to address. Simple models which include wage index or ACOL variables may be adequate for simulating changes within the historical range of variation, particularly for a one time change scenario. It is recommended that the estimated model be subjected to additionai quality control measures such as theoretical implications and predictive content.

Questions pertaining to bonuses payments and retirement benefits are considerably more difficult to address. Bonuses tend to have more dynamic effects of first decreasing and then increasing loss rates. The effect of changes in retirement policy, however, are difficult to predict because there is little historical experience. The problem is additionally complicated because retirement concerns are in the mid to long term future for those in the grade/LOS cells of most concern. 
More detailed models such as the DRM appear necessary to capture adequately the dynamic effects of a temporary pay changes. The DRM does so by modeling an officer's entire service career with an underlying "taste for the service" parameter. The average "taste for the service" decreases as does the loss rate due to the pay inducement's retaining the officers with low "taste for the service", who would have otherwise left. Once the additional pay ends, the loss rate increases as the officers with low "taste for the service" leave.

Detailed analysis of retirement issues requires further research. Ideally, it would desirable to investigate systematically the effect on retention rates of different assumptions of how career decisions are made and the treatment of uncertainty. Gotz and McCall provide evidence in comparing the model of fit of DRM with other ACOL type models. This comparison contrasts one set of assumptions with another, which provides no indication of what assumptions are associated with the improved model fit. An examination of the assumptions individually may indicate that the data cannot really discern between two alternative hypotheses. In this case, policy conclusions which varied with the different alternatives should be identified as ambiguous. It is hoped that such situations may be resolved with additional evidence. 


\section{REFERENCES}

Arguden, R. Y., "Personnel Management in the Military, Effects of Retirement Policies on the Retention of Personnel", The Rand Corporation, R-3342-AF, (January 1986).

Bates, J. M. and C. W. J. Granger, "The Combination of Forecasts." Qperations Research Quarterly, 20, 451-68, 1969.

Bres, E. S. and M. W. Rowe, "Development and Analysis of Loss Rate Forecasting Techniques for the Navy's Unrestricted Line Officers," NPRDC TR 79.20, (June 1979).

Bres, E. S. and M. W. Rowe, "Base Force Retention Rate: An Improved Measure of Navy Officer Retention," NPRDC TR 83-24, (July 1983).

Carter, G. M., "The Effect of Selective Reenlistment Bonuses on Terms of Enlistment in the Air Force," Rand WD-2523-AF, (February 1985).

Chipman, M., "The Navy Officer Force Projection Model," NPRDC Special Report 83-17, (March 1983).

Chipman, M., "STRAP-O Five-Year Verification/Validation Conclusions," Working Paper, (October 1986).

Chipman, M.D. and H. Mumm, "Forecasting Naval Enlisted Retention Behavior under Alternative Retirement Systems," Navy Personnel Research and Development Center, San Diego, Calif., report NPRDC TR-79-4 (1978).

Enns, John H., Gary R. Nelson, and John T. Warner, "The Economics of Retention and Retirement: The Case of the U.S. Military," Policy Science, Vol. 17, 1984.

Fernandez, R. L., G. A. Gotz and R. M. Bell, "The Dynamic Retention Model," Rand, 90406-2138, report N-2141-MIL, (April 1984).

Goldberg, M. S. and J. T. Warner, "Determinants of Navy Reenlistment and Extension Rates," Center for Naval Analyses, 2000 North Beauregard Street, Alexandriı, VA, 22311, report CRC476, 1981.

Goldberg, M. S. and J. T. Warner, "On the Length of Navy Reenlistment Decisions," Economic Analysis Report for NMPC, OP-01, (1983).

Gotz, G. A. and J. J. McCall, "Sequential Analysis of the Stay/Leave Decision: U. S. Air Force Officers," Management Science, Vol. 29, No. 3, pps. 335-351, (March 1983).

Gotz, G. A. and J. J. McCall, "A Dynamic Retention Model for Air Force Officers," Rand, report R3028-AF, (1984).

Granger, C. W. J. and R. Ramanathan, "Improved methods of combining forecasts", Journal of Forecasting, 3, 197-204, (1984). 
Hosek, J. R. and C. E. Peterson, "Reenlistment Bonuses and Retention Behavior," Rand, report R3199-MIL, (March 1985).

Kostiuk, P. F., "Pay and Retention of Marine Corps Aviators," Center for Naval Analysis, report CRM 85-21, (February 1985).

Newbold, P. and C. W. J. Granger, "Experience with Forecasting Univariate Time Series and the Combination of Forecasts," Journal of the Royal Statistical Association, A, 137, 131-46, (1974).

QRMC, Fifth Quadrennial Review of Military Compensation, QRMC V, Vols, I, I-A, I-B, I-C, (January 1984).

Siegel, B., "Methods for Forecasting Officer Loss Rates," Navy Personnel Research and Development Center, San Diego, Calif., report NPRDC TR 83-30, (August 1983).

Siegel, B., "STRAP-O Five-Year Verification/Validation Conclusions," Navy Personnel Research and Development Center, San Diego, Calif., a draft unpublished report, (1986).

Smoker, R. E., "Annualized Cost of Leaving Model," Fifth Quadrennial Review of Military Compensation, Vol. 1B, Appendix I, (January 1984).

Warner, J. T., "Alternative Military Retirement Systems: Their Effects on Enlisted Retention," Center for Naval Analyses, CNA research contribution 376, (1979).

Warner, J. T., "Issues in Navy Manpower Research and Policy: An Economist's Perspective," Center for Naval Analyses, Alexandria, Virginia, CNA Professional Paper 322, (1981).

Warner, J. T. "Military Compensation and Retention: An Analysis of Alternative Models and a Simulation of a new Retention Model," Center for Naval Analyses, report CRC 436, (August 1981).

Warner, J. T. and Goldberg, M.S. "The Influence of Nonpecuniary Factors on Labor Supply," Center for Naval Analyses, report 337, (December 1981A).

Warner, J. T. and M. S. Goldberg, "The Influence of Nonpecuniary Factors on Labor Supply," Center for Naval Analyses, Alexandria, Virginia, report CRC 337, (December 1981B).

Warner, J. T. and M. S. Goldberg," Determinants of Navy Reenlistment and Extension Rates," Center for Naval Analyses, Alexandria, Virginia, report CRC 476 (December 1982).

Warner, J. T. and M. S. Goldberg, "The Influence of Nonpecuniary Factors on Labor Supply: The Case of Navy Enlisted Personnel," Journal Unknown, pps. 26-35, (1983).

Warner, J. T. and B. Simon, "An Empirical Analysis of Pay and Navy Enlisted Retention in the AVF," Center for Naval Analyses, Alexandria, Virginia, CNR Memorandum 79-1978, (1981). 

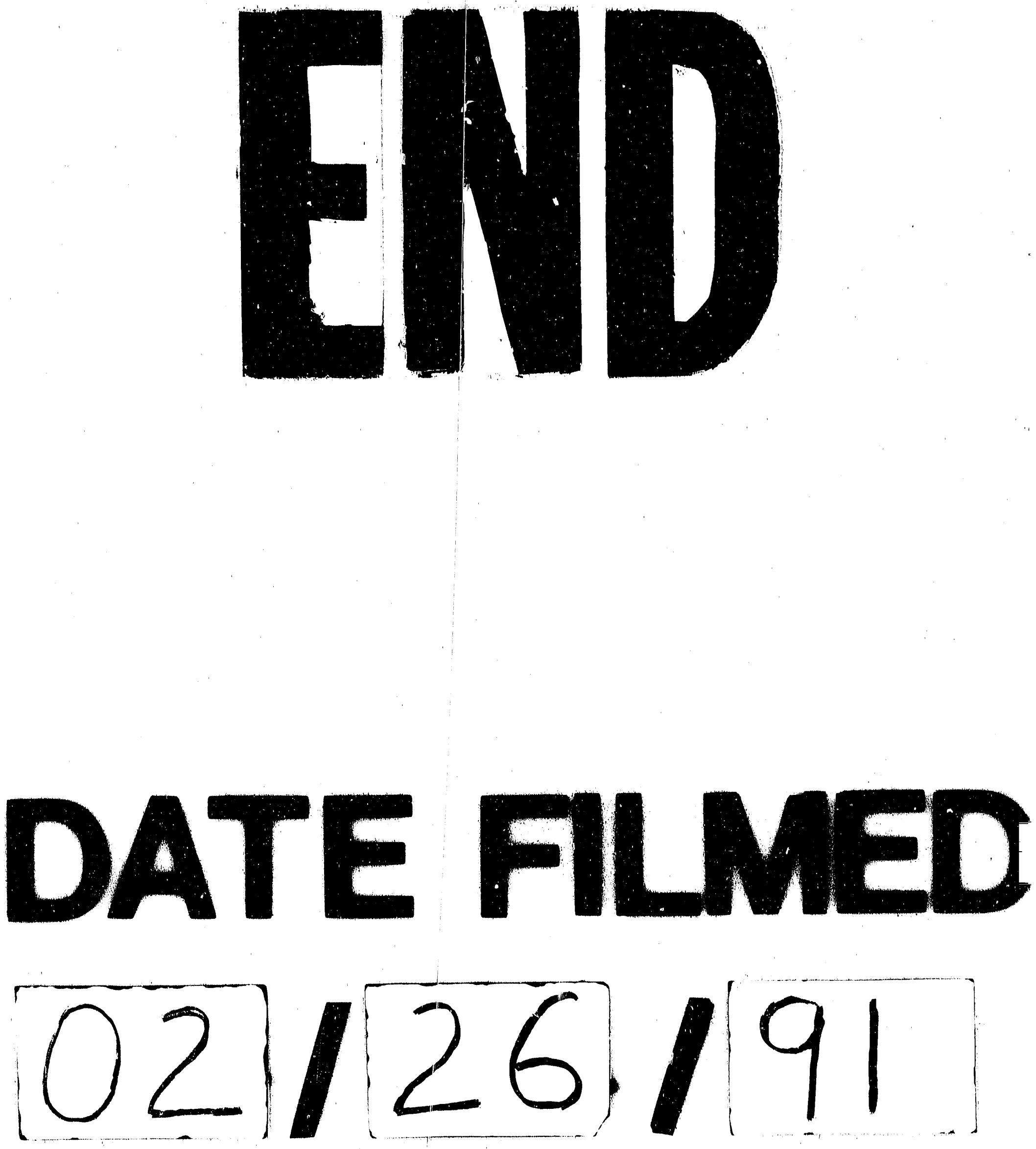
